\section{A CAUSE OF INTESTINAL OBSTRUCTION AFTER GASTRO-ENTEROSTOMY.}

By H. M. W. GRAY, M.B., C.M. Aberd., F.R.C.S. EdIN., SURGEON TO THE ABERDEEN ROYAL INTIRMARY.

THE patient, an unmarried woman, aged 31 years, was seen by me in consultation on the evening of May 15th, 1904. For some months she had suffered from severe " indigestion," intense epigastric pain, radiating to the back, occurring almost immediately after taking food. She had not vomited during this period but had noticed that the stools were very dark on several occasions. On May 14th she became suddenly collapsed and vomited a large quantity.of blood. In spite of medical treatment the hæmatemesis was repeated several times, although not to such a large extent.' The bowels were opened and the stool contained a large quantity of blood. On the evening of the 15th she became again so collapsed that death was thought to be imminent. She had recovered somewhat before I saw her. Her pulse was very feeble and irregular. It was occasionally as low as 120 but was usually considerably quicker. It was estimated that she had vomited between two and three pints of blood. By' percussion of the shifting dulness, limited to the gastric area, it was found that the stomach contained at least a pint of blood. Nothing had been given by the mouth since the onset of the attack. 'These facts, considered along with the presence of the large quantity of blood in the stool, made the total blood lost amount to probably between four and five pints. It seemed that the bleeding had stopped and it was thought advisable to wait until the morning, as transference to hospital would have had a severe effect on the patient in her perilous condition. Morphine was given hypodermically and a careful watch was set. She passed a fairly good night but early the next morning she again vomited blood and was removed to hospital. On arrival there she vomited a small quantity of fresh blood, so an operation was carried out at once.

Chloroform was administered and three pints of saline solution were slowly infused into a vein at the elbow. The stomach was exposed by a free incision. Blood was seen to be present in a large amount in the stomach and in the whole length of the intestines. Nothing else abnormal about the stomach was detected by inspection or palpation. The blood was squeezed through the pylorus, the stomach was opened posteriorly and its interior was inspected. No ulcer was seen. A posterior retrocolic gastro-enterostomy was performed. Sutures alone were used.

The patient vomited early on the second day after operation. The vomit contained a small amount of "coffeeground" material and was foul smelling. Five minims of liquid extract of cascara sagrada were given every hour but after three doses she became sick so it was intermitted for 12 hours and then begun again. An enema was given on the evening of the day of operation to clear the rectum; a tarry motion resulted. Every second day thereafter an enema was administered. On the fourth day the stool was free from blood.

About noon on the sixth day she complained of intermittent griping pain in the abdomen. This continued until the evening when it abated somewhat. It was thought probably to be due to flatus, although previously to this a turpentine enema brought away neither flatus nor fæces. A small dose of morphine was given. She was quite comfortable till $3 \mathrm{~A}$.M. on the morning of the seventh day, when the pains began again and increased in severity as the effect of the morphine passed off. Vomiting occurred on two occasions. At 9 A.M. another turpentine enema was given but with no result. The facial expression was now somewhat drawn and anxious. Vomiting continued at intervals but the pains subsided considerably after the enema. The temperature and the pulse were unaffected. The latter had become reduced in frequency from 144 on the day of operation to $100-110$.

Intestinal obstruction was diagnosed and immediate operation was advised. This was declined. I prescribed two drachms of magnesium sulphate by the mouth and eight minims of liquor strychninæ hypodermically. The immediate effect of this was to produce severe colicky pain and acquiescence in operation which was carried out at 4 P.M. It was then found that practically the whole of the small intestine had insinuated itself from left to right through the ring formed at the first operation by the peritoneum of the under layer of the mesocolon, that lining the posterior abdominal wall and forming the upper layer of the mesen. tery, and completed anteriorly by the gastro-jejunal junction. It was easily pulled back and the ring closed by suturing the under layer of the mesocolon to the upper layer of the mesentery to prevent recurrence of the hernia. Strangely enough, there was enormous distension of the colon with gas. It was found to be quite patent down to the rectum. It was accordingly punctured by a trocar and cannula and the gas let out. A silk suture was inserted to close the opening made by the trocar and a piece of omentum was stitched over that. "The gastro-jejunal junction was found to be perfect. The patient vomited once during the evening after the operation but therealter recovery was uninterrupted and she left the hospital on June 13th. She was seen on July 5th, when she looked extraordinarily well. She had suffered no pain, no indigestion, and no vomiting since her dismissal. The stools had been normal. She now made $n$ o restrictions in her diet.

I can find no record in the literature on gastro-enterostomy of such a post-operative condition. Moynihan mentions the occurrence in one of his cases of hernia into the lesser peritoneal sac through the opening, made at the operation, in the mesocolon. This, I think, was discovered post mortem. Both these forms of hernia can, of course, be prevented by the insertion of a few sutures, My action in administering drugs to produce increased peristalsis and pain in order to promote acquiescence in operation has been called in question by some of my medical brethren. I have no doubt of its justifiability. Had I left the patient alone and allowed the pains to develop in strength gradually she probably would not have agreed to operation for another 24 hours when her condition would have been much worse. In cases of acute intestinal obstruction there is often a lull in the symptoms after the storm of onset. This lull is too frequently augmented and prolonged by the use of morphine. I have also frequently noted an abatement after an enema has been administered and it was during such a lull that the subject of these remarks refused operation. For some years I have hinted that such a use of intestinal stimulants might be made and that the result would strengthen the diagnosis in cases of suspected intestinal obstruction but I should by no means advocate their use unless in very exceptional cases.

Aberdeer.

\section{(illinical alotes:}

\section{MEDICAL, SURGICAL, OBSTETRICAL, AND} THERAPEUTICAL.

\section{A CASE OF CONGENITAL ABSENCE OF ONE TIBIA.}

By H. Lentox MunRo, M.B., CH.B. Edin.

HOLSE SLRGÁTOY 'TO THE ROTAL LAYCASTER INFIRMARY,

A CONGENITAL condition of deficiency or total absence of one or more of the bones of the body is not uncommon and in most cases results in the production of great deformity. Total absence of the tibia would appear to be met with very rarely, the radii being the bones which are most frequently wanting. Cases of absent tibia have been recorded by Bland-Sutton in the Transactions of the Pathological Society of London, vol, xliii., p. 124; by Treves in his "System of Surgery"; and by Parker in THE LANCET of May 27th, 1882, p. 870. For permission to publish the present case I am indebted to Mr. A. S. Barling, honorary surgeon to the Royal Lancaster Infirmary. In the cases described by the above observers the condition was associated with other pathological features, as absence of the radii and the presence of supernumerary digits. In this case the patient was a man, aged 27 years, of short stature and slight build, and the other limbs did not present any abnormal features. 'The appearance of the deformed limb is well seen in Fig. 1 and the actual ontline of the bones is shown in the skiagram (Fig. 2). The thigh was wasted, the muscles being poorly developed; the patella was absent and no signs of the tibia could be made 